\title{
The Treatment Strategy in A Case of Concomitant Left Renal Cell Carcinoma and Left Atrial Myxoma
}

\author{
Rudin Domia, ${ }^{\mathrm{a}}$, Ilir Ohria ${ }^{\text {, Hektor Sula }}{ }^{\mathrm{a}}$
}

\begin{abstract}
This case report describes the treatment plan of a patient with concomitant left renal cell carcinoma and incidentally discovered left atrial myxoma. Myxomas are cardiac benign tumors, mainly located in left atrium. Clinical symptoms or complications are embolic related events or valvular dysfunction, causing even cardiac arrest. In such a pathologic situation the treatment strategy includes: correct identification of all the possible problems (diagnoses) and the plan of surgical priorities. Careful examination, shorter cardiopulmonary bypass period, good blood pressure and volume status, and perioperative renal protection can guarantee good outcome of the patient.
\end{abstract}

Keywords: Anesthesia; Cardiac surgery; Myxoma; Renal cell carcinoma

\section{Introduction}

This case report describes the anesthetic management of a patient with concomitant left renal cell carcinoma and incidentally discovered left atrial myxoma.

Renal cell carcinoma accounts for approximately $3 \%$ of adult malignancies and $90-95 \%$ of neoplasms arising from the kidney [1]. Von Hippel-Lindau syndrome, hereditary papillary renal carcinoma, familial renal oncocytoma associated with Birt-Hogg-Dube syndrome, and hereditary renal carcinoma are often associated with renal cell carcinoma. The metastatic disease occurs mostly in lung, soft tissue, bone, liver, central nervous system, and as metastatic

\footnotetext{
Manuscript accepted for publication November 17, 2010

${ }^{\text {a}}$ University Hospital Center 'Mother Theresa', Department of Anesthesia and Intensive Care, Tirana, Albania

bCorresponding author: rudilaureta@hotmail.com
}

doi:10.4021/jmc83w thrombus in inferior caval vein and right atrium [1]. There is no case in the current medical literature which described the concomitance of left renal cell carcinoma and left atrial myxoma.

Myxomas are the most common type of cardiac benign tumors [2]. Eighty-five percent are located in the left atrium (LA), $15 \%$ in the right atrium (RA), in both atria, or in the ventricles [3]. Approximately $10-15 \%$ of patients are asymptomatic and the diagnosis is made incidentally, and 85 $\%$ have clinical symptoms embolic related events or valvular dysfunction $[2,4]$. Echocardiography is usually the first imaging modality to detect a cardiac mass. The echocardiographic localization of the mass and eventual clinical symptoms may be strongly suggestive of myxoma in the light of potential differential diagnosis such as thrombi. The most common differential diagnosis of atrial myxoma is thrombus formation [2]. More recently it has been suggested that cardiac magnetic resonance imaging (MRI) may play a significant role by demonstrating specific findings in favor of myxoma. Regarding the literature, this is the first case which describes the concomitant left renal cell carcinoma and incidentally discovered left atrial myxoma.

\section{Case Report}

A 51 years old woman (body weight $61 \mathrm{~kg}$, height $169 \mathrm{~cm}$, ASA I), without significant previous medical history, was consulted by an urologist because of left flank moderate pain. She underwent an ultrasound examination, during which a left kidney tumor was verified. She also underwent angiocomputed tomography (CT) (Fig. 1) scan and MRI examination in order to make tumor stratification and verify possible conflicts with the great vessels as well. These examinations incidentally discovered a formation in left atrium. The patient was consulted by a cardiologist and a cardio surgeon, and then underwent echocardiography (Fig. 2) and coronarography examination. The diagnosis of left atrial myxoma was made (no vascularization by coronary arteries). Clinical assessment, chest $\mathrm{x}$-ray and laboratory findings were normal. The patient was premedicated with oral Diazepam $10 \mathrm{mg}$ the night before the surgery, and morphine sulfate $10 \mathrm{mg}$ intra- 


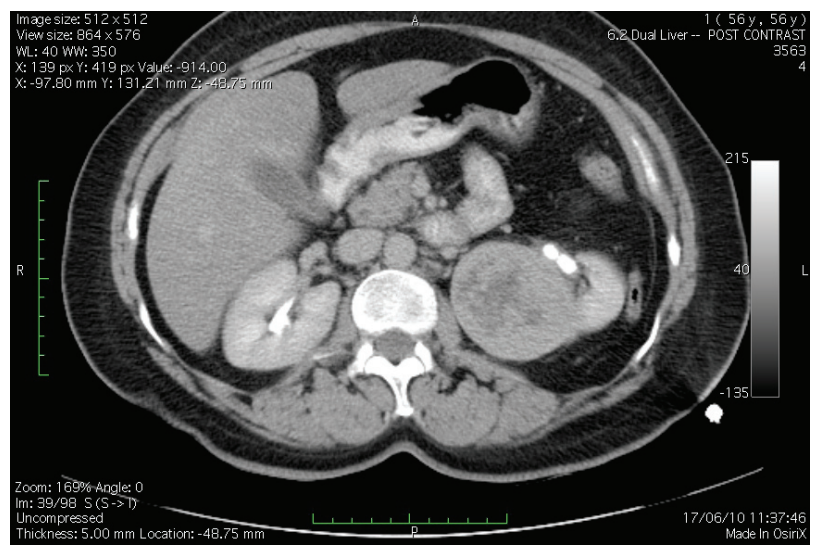

Figure 1. Angio-CT scan view of the patient, demonstrating left kidney tumor.

muscularly 30 minutes before the induction of anesthesia. In operating room, after peripheral venous cannula was inserted, right radial artery and right internal jugular vein were cannulated with a $20 \mathrm{G}$ arterial cannula and $7.5 \mathrm{~F}$ central venous catheter. A fast track anesthesia was made (fentanyl $5 \mathrm{mg} / \mathrm{kg}$, propofol $2 \mathrm{mg} / \mathrm{kg}$, cisatracurium $0.15 \mathrm{mg} / \mathrm{kg}$ ). Monitoring included invasive arterial monitoring, central venous pressure, ECG, temperature, urine output, and endTidal carbon dioxide. The anesthesia was maintained with sevoflurane, propofol infusion, fentanyl and cisatracurium as needed. An open heart surgery with cardiopulmonary bypass was performed. Perioperative period was uneventful, dealing with renal protection with good mean arterial pressure (MAP), volume maintenance, furosemide and fenoldopam. An open radical left nephrectomy was performed 3 weeks later. The surgery and postoperative period were uneventful and the patient was discharged in 4th postoperative day.

\section{Discussion}

The first issue was to diagnose the formation situated at the left atrium. It should be identified if it was a tromb, myxoma or a metastase causd by the renal tumor.

In patients with diagnosis of myxoma, a surgical intervention is strongly recommended. In patients with cardiac thrombus a period of anticoagulation therapy may be warranted, whereas in case of metastasis probably the surgery would not be the best choice.

Renal cell carcinoma accounts for approximately $3 \%$ of adult malignancies and $90-95 \%$ of neoplasms arising from the kidney. Several hereditary syndromes are associated with renal cell carcinoma such as: von Hippel-Lindau syndrome, hereditary papillary renal carcinoma, familial renal oncocytoma associated with Birt-Hogg-Dube syndrome, and
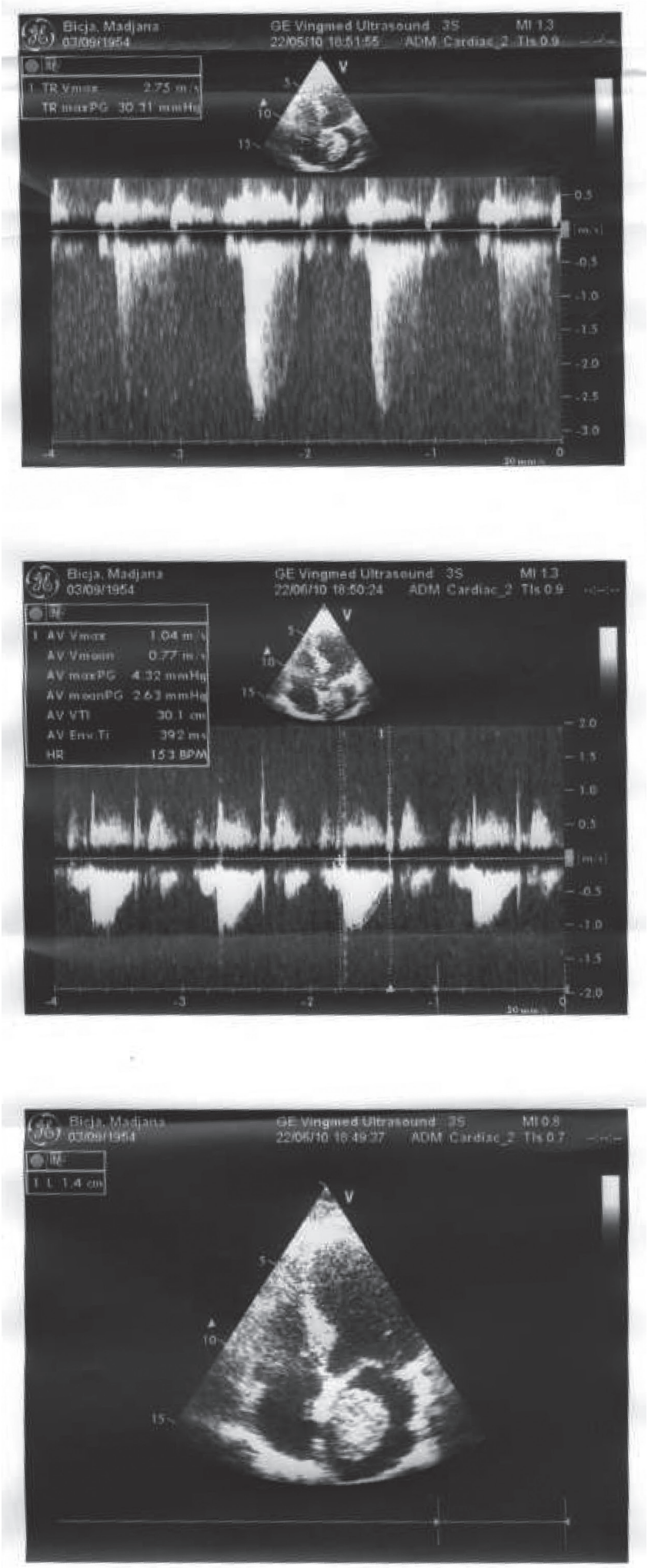

Figure 2. Echocardiography examination confirmed left atrial myxoma. 
hereditary renal carcinoma. Approximately $30 \%$ of patients with renal carcinoma present with metastatic disease including: lung (75\%), soft tissues (36\%), bone (20\%), liver (18\%), cutaneous sites $(8 \%)$, and central nervous system (8\%). In approximately $5-10 \%$ of patients, the tumor extends in the renal vein, inferior vena cava and right atrium as a thrombus. The classic signs as hematuria, flank pain, and palpable mass are presented in $10 \%$ of the patients. Mostly this tumor is incidentally diagnosed by a routine abdominal ultrasound examination. Once the diagnosis is made, several examinations are perhaps required like computerized tomography (CT), magnetic resonance (MRI), and/or renal angiography (RA). Our patient underwent all the examinations mentioned above for renal cell carcinoma diagnosing, which incidentally discovered left atrial myxoma in MRI. Then our patients made echocardiography and coronary angiography (CA) despite it's low sensitivity and specificity. Echocardiography is usually the first imaging modality which leads to the diagnosis of a cardiac mass. It provides information about its size, localization and mobility. However, echocardiographic findings are not specific and discrimination between primary cardiac tumors, such as myxoma, and other cardiac masses remains challenging [5]. The most common differential diagnosis of cardiac myxoma is atrial thrombi $[2,6]$. Clinical symptoms may be similar particularly with respect to intracardiac obstruction and peripheral embolization. CA may be a useful tool in further differentiating between cardiac tumor and thrombi. Cardiac tumors such as myxomas are considered highly vascularized. Furedi et al reported signs of neovascularization in five out of nine $(56 \%)$ cardiac myxoma patients [7]. These findings of neovascularization were in favor of tumoral nature of cardiac mass allowing differentiation from atrial thrombi. Therefore, the value of CA in differentiating cardiac masses between tumors such as myxoma and thrombi remains limited. Despite the lack of sensitivity and specificity, some authors have, however, suggested that CA should be performed systematically in patients with cardiac myxoma to detect a large supplying vessel [8]. Our patient had no neovascularization by coronary arteries. We believe that $\mathrm{CA}$ is of limited interest in determining the etiology of an intracardiac mass. MRI provides specific information about tissue characteristics that facilitate the differentiation between myxoma and thrombi. These findings are characteristic of myxomas and differentiate them from other tumors which show different signal intensity [9]. In addition, myxomas typically show a heterogeneous appearance in MRI, due to areas of necrosis, hemorrhage or calcification. These findings were consistent in our patient. Cardiac CT is increasingly used for noninvasive $\mathrm{CA}$ and may be an alternative modality for the assessment of cardiac masses.

The second issue was setting of the priorities, so if we had to first left radical nephrectomy or myxoma, or both in the same time.

We thought that both intervents could not be done in the same time because of the risk for renal failure and bleeding by anticoagulation during cardiopulmonary bypass. Surgery should, therefore, be performed promptly after the diagnosis is made to avoid potential complications such as peripheral embolization or cardiac valvular obstruction. So it was decided to begine with myxoma intervent, to proceed in a second phase with left kidney removal. So our patient first underwent to cardiac surgery to remove the myxoma. We didn't find any author who supported the idea that cardiopulmonary bypass would be contraindicated in malignancy because of tumor spreading risk [10-12].

The third issue was renal protection and prevention of the possible renal failure.

The preservation of renal function was very important to our patient, because of later surgery which consisted in radical left kidney removal. Cardiac surgery and cardiopulmonary bypass are well known as events related to perioperative renal failure. All organs are potential sites of dysfunction during cardiac surgery and cardiopulmonary bypass. Renal complication may be evident almost immediately [13]. Nevertheless the incidence of renal failure ranges between $2-35 \%$ depending more on preoperative renal function, type of surgery, diabetes, age older than 70 years, and hemodynamic status. The incidence increases dramatically if there is preoperative renal dysfunction [14-16]. Several mechanisms explain the possible perioperative renal dysfunction. These include hypotension, nonpulsatile flow which promotes vasoconstriction and decreases renal blood flow, glomerular filtration, and urine output. Intravascular hemolysis can cause acute tubular necrosis too. So the cardiopulmonary bypass period was short, we took care about blood pressure, volume status, good diuresis using furosemide, and of course avoiding renal hypoperfusion and vasoconstriction using fenoldopam.

As a conclusion we conclude that the role of diagnostic evaluation and the determination of surgical priorities are the main factors in achieving the successful outcome in the treatment of above mentioned concomitant pathologies.

\section{Conflict of Interest}

The authors declare no conflicts of interests.

\section{References}

1. Whalley DG, Berrigan MJ. Anesthesia for radical prostatectomy, cystectomy, nephrectomy, pheochromocytoma, and laparoscopic procedures. Anesthesiol Clin North America 2000;18(4):899-917, x.

2. Reynen K. Cardiac myxomas. N Engl J Med 1995;333(24):1610-1617.

3. Butany J, Nair V, Naseemuddin A, Nair GM, Catton C, 
Yau T. Cardiac tumours: diagnosis and management. Lancet Oncol 2005;6(4):219-228.

4. Pinede L, Duhaut P, Loire R. Clinical presentation of left atrial cardiac myxoma. A series of 112 consecutive cases. Medicine (Baltimore) 2001;80(3):159-172.

5. Perez de Isla L, de Castro R, Zamorano JL, Almeria C, Moreno R, Moreno M, Lima P, et al. Diagnosis and treatment of cardiac myxomas by transesophageal echocardiography. Am J Cardiol 2002;90(12):1419-1421.

6. Nemirovsky D, Salzberg SP, Einstein AJ, Abascal VM, Karlof E, Sanz J, Rajagopalan S, et al. Multimodal characterization of a large right atrial mass after surgical repair of an atrial septal defect. Mt Sinai J Med 2006;73(8):1117-1119.

7. Fueredi GA, Knechtges TE, Czarnecki DJ. Coronary angiography in atrial myxoma: findings in nine cases. AJR Am J Roentgenol 1989;152(4):737-738.

8. Janas R, Jutley RS, Fenton P, Sarkar P. Should we perform preoperative coronary angiography in all cases of atrial myxomas? Catheter Cardiovasc Interv 2006;67(3):379-383.

9. Sparrow PJ, Kurian JB, Jones TR, Sivananthan MU. MR imaging of cardiac tumors. Radiographics 2005;25(5):1255-1276.

10. Kouchoukos NT, Blackstone EH, Doty DB, et al. Hypo- thermia, circulatory arrest, and cardiopulmonary bypass. In: Kirklin JW, Barratt-Boyes BG. Cardiac surgery, 3rd Ed. New York: Churchill Livingstone, 2003: 75-81.

11. Stammers AH, ed. Cardiopulmonary bypass: emerging trends and continued practices. Intl Anesthesiol Clin $1996 ; 34$.

12. Gravelee GP, Davis RF, Kurusz M,eds. Cardiopulmonary bypass: principles and practice, 3rd ed. Philadelphia: Lippincott Williams Willkins, 2007.

13. Hessel EA, 2nd. Abdominal organ injury after cardiac surgery. Semin Cardiothorac Vasc Anesth 2004;8(3):243263.

14. Higgins TL, Estafanous FG, Loop FD, Beck GJ, Blum JM, Paranandi L. Stratification of morbidity and mortality outcome by preoperative risk factors in coronary artery bypass patients. A clinical severity score. JAMA 1992;267(17):2344-2348.

15. Aronson S, Blumenthal R. Perioperative renal dysfunction and cardiovascular anesthesia: concerns and controversies. J Cardiothorac Vasc Anesth 1998;12(5):567586.

16. Bove T, Calabro MG, Landoni G, Aletti G, Marino G, Crescenzi G, Rosica C, et al. The incidence and risk of acute renal failure after cardiac surgery. J Cardiothorac Vasc Anesth 2004;18(4):442-445. 